\title{
Introduction: Managing the Innovative Development of Economic Systems as a Challenge for the Modern Economics and Law
}

Innovative development is one of the most important manifestations of the modern economic systems, which gives them a range of advantages. Firstly, innovations have a counter-cyclical influence on economic systems, allowing preventing and overcoming economic crises. Innovations accelerate economic growth and create new jobs, ensuring employment and growth of population's incomes. At the same time, innovations could be the causes of crises - e.g., technological changes in the stock market became a reason of the 2008 crisis, and technological changes cause unemployment due to expansion of automatizaton - which was observed during each industrial revolution.

Secondly, technological progress stimulates the increase of quality of life. New benefits become accessible, ensuring the improved satisfaction of society's needs. Innovations could raise the level of social justice, level social disproportions, and stimulate social integration. Digitization, for example, erases geographical borders and ensures global communication of people. However, new inventions could pose a threat for human health and environment, causing a delayed effect. For example, the fuel \& energy achievements of the 20th century in the sphere of car building and nuclear energy became a reason of ecological crises in the 21st century - mass pollution of air from wide use of cars, disasters at nuclear power plants, etc.

Thirdly, innovations move competition, increasing the effectiveness of economic systems. Innovations allow achieving competitive advantages and increasing the economic systems' competitiveness. At the same time, competition could be destructive - when investments in innovations are not returned, do not bring profit, and are aimed only at undermining the rivals' positions in the target market. Competition could also be false - when economic systems copy and adapt each other's technologies instead of creating new ones. The risks of innovative activities could be manifested in negative results of $R \& D$, due to which investments in them will not be returned.

Fourthly, innovations allow realizing human potential, which is accumulated by economic systems. Progress conforms to the logic of society's development, and its absence causes social tension. High level of education, which has been achieved though, to a different extent - in all modern economic systems, requires the application of population's intellectual capabilities. However, in case of the network form of organization of entrepreneurship, innovative development could take place only in the economic system with the intellectual \& managerial center; in other economic systems, where production is located, skilled workers are not required, for cheap labor resources or automatization means are used. 
Thus, advantages of innovative development are contradictory, and its regulation is a "market gap", which could be overcome by state regulation. Innovations management allows balancing private commercial advantages from the innovative activities and the public interests of innovative development, as well as preventing the negative consequences and increasing the probability of obtaining profit from the innovative activities. This complex task on managing the innovative development of economic systems is a challenge for the modern economics and law and is an important scientific and practical problem.

This book aimed at developing a scientific basis of economic \& legal management of innovative development of modern economic systems. The book contains seven parts, which dwell on the essence and perspectives of solving the set problem. Part I considers the theoretical foundations and the methodology of managing the innovative development of economic systems, as well as conceptual approach to studying innovations and their paradigm modern treatment. Innovations are studied as opposed to traditions. The economic and legal mechanism of managing the innovative development of a modern economic system is determined.

Part II is devoted to evaluation of effectiveness of economic systems' innovative development. Effectiveness is treated as the key criterion of successfulness of managing the innovative development of modern economic systems. The indicators of effectiveness of economic systems' innovative development are given, and the methodological approach to evaluating the effectiveness of economic systems' innovative development is offered.

Part III forms the legal foundations of managing the innovative development of economic systems. The modern institutions of managing the innovative development of economic systems and the standards and norms of managing the innovative development of modern of economic systems are described. The role of international organizations in managing the innovative development of modern economic systems is formulated.

Part IV is contains the overview of the modern practical experience of economic \& legal management of economic systems' innovative development. The authors determine specific features of economic \& legal management of innovative development of modern economic systems in developed countries and outline the economic \& legal specifics of managing the innovative development of modern economic systems in developing countries. The specifics of economic \& legal management of innovative development of the modern Russia's economic system are also considered.

Part V sets the current economic \& legal problems of managing the innovative development of economic systems. The authors dwell on the economic \& legal gaps in managing the innovative development of modern economic systems, substantiate inconsistency and imbalance of managing the innovative development of modern economic systems, and analyze the global disproportions in managing the innovative development of developed and developing countries. 
Part VI contains recommendations for economic \& legal management of economic systems' innovative development. A concept of consistent and well-balanced economic \& legal management of innovative development of modern economic systems is offered; a perspective algorithm of economic \& legal management of innovative development of modern economic systems is compiled; and a model of leveling the global disproportions in managing the innovative development of modern economic systems is created. Future scenarios of innovative development of the global economic system depending on the economic \& legal specifics of this process management are determined.

Elena G. Popkova, Aleksei V. Bogoviz and Artem I. Krivtsov 
